\title{
Screening for prevention of optic nerve damage due to chronic open angle glaucoma (Review)
}

\author{
Hatt SR, Wormald R, Burr J
}
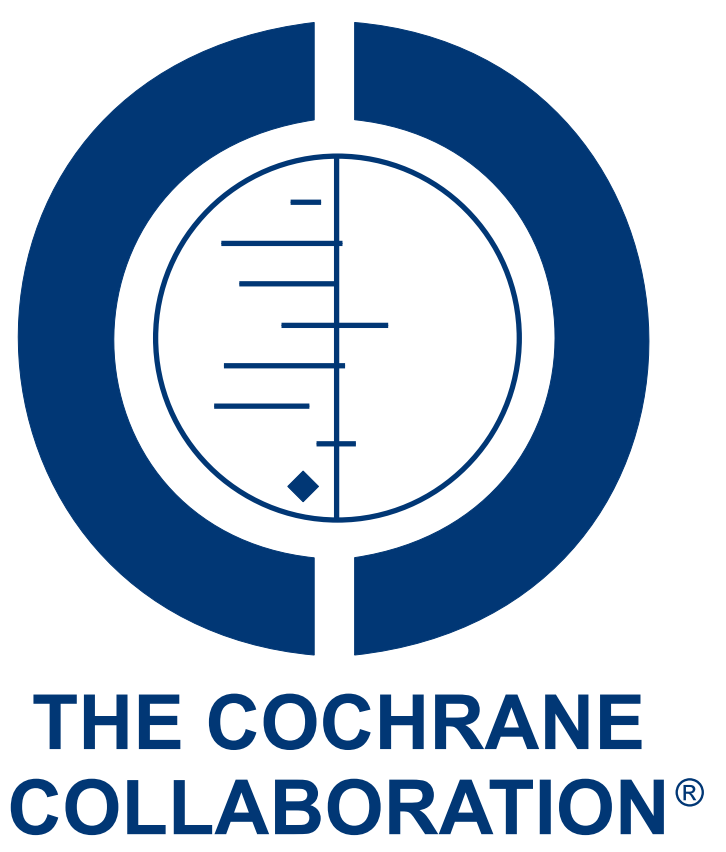

This is a reprint of a Cochrane review, prepared and maintained by The Cochrane Collaboration and published in The Cochrane Library 2006, Issue 4

http://www.thecochranelibrary.com

\section{WILEY}

Screening for prevention of optic nerve damage due to chronic open angle glaucoma (Review)

Copyright $\odot 2009$ The Cochrane Collaboration. Published by John Wiley \& Sons, Ltd. 
TABLE OF CONTENTS

HEADER . . . . . . . . . . . . . . . . . . . . . . . . . . . . . . . . . . . . 1

ABSTRACT . . . . . . . . . . . . . . . . . . . . . . . . . . . . . . . . . . . . . . . . . . . . . . .

PLAIN LANGUAGE SUMMARY . . . . . . . . . . . . . . . . . . . . . . . . . . . . . . . . . . . 2

BACKGROUND . . . . . . . . . . . . . . . . . . . . . . . . . . . . . . . . . . . . . . . . .

OBJECTIVES . . . . . . . . . . . . . . . . . . . . . . . . . . . . . . . . . . . . .

METHODS . . . . . . . . . . . . . . . . . . . . . . . . . . . . . . . . . . . . . .

RESULTS . . . . . . . . . . . . . . . . . . . . . . . . . . . . . . . . . . . . . . . 8

DISCUSSION . . . . . . . . . . . . . . . . . . . . . . . . . . . . . . . . . . . . . 8

AUTHORS' CONCLUSIONS . . . . . . . . . . . . . . . . . . . . . . . . . . . . . . . . . . 8

ACKNOWLEDGEMENTS . . . . . . . . . . . . . . . . . . . . . . . . . . . . . . . . . . 9

REFERENCES . . . . . . . . . . . . . . . . . . . . . . . . . . . . . . . . . . . . . . . 9

DATA AND ANALYSES . . . . . . . . . . . . . . . . . . . . . . . . . . . . . . . . . . . . . . 12

APPENDICES . . . . . . . . . . . . . . . . . . . . . . . . . . . . . . . . . . . . . . . . . .

WHAT'S NEW . . . . . . . . . . . . . . . . . . . . . . . . . . . . . . . . . . . . . . 14

HISTORY . . . . . . . . . . . . . . . . . . . . . . . . . . . . . . . . . . . . . . . . 14

CONTRIBUTIONS OF AUTHORS . . . . . . . . . . . . . . . . . . . . . . . . . . . . . . . . 15

DECLARATIONS OF INTEREST . . . . . . . . . . . . . . . . . . . . . . . . . . . . . . . . . . . . .

SOURCES OF SUPPORT . . . . . . . . . . . . . . . . . . . . . . . . . . . . . . . . . . . . . . . . . . .

INDEX TERMS . . . . . . . . . . . . . . . . . . . . . . . . . . . . . . . . . . . . . . . . . . . . . . . . 16 


\title{
[Intervention Review]
}

\section{Screening for prevention of optic nerve damage due to chronic open angle glaucoma}

\author{
Sarah R Hatt ${ }^{2}$, Richard Wormald ${ }^{1}$, Jennifer Burr ${ }^{3}$ \\ ${ }^{1}$ Cochrane Eyes and Vision Group, ICEH, London School of Hygiene \& Tropical Medicine, London, UK. ${ }^{2}$ Ophthalmology Research, \\ Mayo Clinic, Rochester, USA. ${ }^{3}$ Health Services Research Unit, University of Aberdeen, Aberdeen, UK \\ Contact address: Richard Wormald, Cochrane Eyes and Vision Group, ICEH, London School of Hygiene \& Tropical Medicine, Keppel \\ Street, London, WC1E 7HT, UK. r.wormald@ucl.ac.uk.
}

Editorial group: Cochrane Eyes and Vision Group.

Publication status and date: New search for studies and content updated (no change to conclusions), published in Issue 2, 2009.

Review content assessed as up-to-date: 11 January 2009.

Citation: Hatt SR, Wormald R, Burr J. Screening for prevention of optic nerve damage due to chronic open angle glaucoma. Cochrane Database of Systematic Reviews 2006, Issue 4. Art. No.: CD006129. DOI: 10.1002/14651858.CD006129.pub2.

Copyright (C) 2009 The Cochrane Collaboration. Published by John Wiley \& Sons, Ltd.

\begin{abstract}
A B S T R A C T

\section{Background}

Open angle glaucoma (OAG) is a primary, progressive optic neuropathy; the onset is without symptoms and progression occurs silently until the advanced stages of the disease, when it affects central vision. The blindness caused by OAG is irreversible. It has often been assumed to be a condition that fulfils the criteria for population screening, although this has not been supported by other in-depth non-systematic reviews. The focus of this review was to examine the evidence for the effectiveness of screening for OAG.
\end{abstract}

\section{Objectives}

To determine the impact of screening for OAG compared with opportunistic case findings or current referral practices on the prevalence of and the degree of optic nerve damage due to OAG in screened and unscreened populations.

\section{Search methods}

We included any randomised controlled trial (RCT) evaluating population-based screening programmes for OAG with a minimum one year follow up. We searched the Cochrane Central Register of Controlled Trials (CENTRAL) (which contains the Cochrane Eyes and Vision Group Trials Register) (The Cochrane Library, Issue 4, 2008), MEDLINE (January 1950 to January 2009), EMBASE (January 1980 to January 2009), the UK Clinical Trials Gateway (UKCTG) and ZETOC (January 1993 to January 2009). There were no language or date restrictions in the search for trials. The electronic databases were last searched on 12 January 2009.

\section{Selection criteria}

We planned to include RCTs, including cluster RCTs.

\section{Data collection and analysis}

Two review authors independently assessed the study abstracts identified by the electronic searches. We did not find any trials that met the inclusion criteria.

\section{Main results}

As no trials were identified, no formal analysis was performed.

Screening for prevention of optic nerve damage due to chronic open angle glaucoma (Review)

Copyright $\odot 2009$ The Cochrane Collaboration. Published by John Wiley \& Sons, Ltd. 


\section{Authors' conclusions}

On the basis of current evidence, population-based screening for chronic OAG cannot be recommended, although much can be done to improve awareness and encourage at risk individuals to seek testing. In wealthy countries with equitable access to high quality eye care and health education, blindness from chronic OAG should become increasingly rare; much greater challenges face poor and emerging economies and countries where there are substantial health and wealth inequalities. Effectiveness of screening for OAG can be established only by high quality RCTs.

\section{PLAIN LANGUAGE SUMMARY}

\section{Screening to prevent damage to the optic nerve due to open angle glaucoma}

Open angle glaucoma (OAG) is the commonest type of glaucoma in white European and African people and is the commonest cause of irreversible blindness. Its onset is insidious and progression symptomless until the condition is far advanced and central vision is lost. Because of this, OAG is assumed to be a condition which should be screened for, but good evidence to support this is lacking. Risk factors for developing OAG include increasing age, raised pressure inside the eye and a history in the family. It is more common in people with African origin, may come on at an early age and is more aggressive. The field of vision (side vision) is gradually lost but changes in the appearance of the optic nerve (where it appears inside the back of the eye) usually occur first. Raised pressure inside the eye may not be present and many with raised pressure do not have glaucoma. Tests for the disease are examination of the optic nerve, measurement of eye pressure and visual field assessment. The challenge of screening is to find people with the disease at a stage when the diagnosis is not in doubt and at risk of going blind if left untreated.

The aim of this review was to determine the impact of screening on the prevalence and severity of optic nerve damage due to OAG. We searched for randomised controlled trials (RCTs) of screening versus no screening for OAG because effectiveness of screening as a means of preventing the ill effects of a disease in a population can only be demonstrated by RCTs. We identified 1360 reports of studies but none were RCTs of screening. Therefore, there is insufficient evidence to recommend population based screening for OAG. However much can be done to improve awareness of the condition and encourage those at higher risk to seek testing. In wealthy countries where there is access to high quality eye care and good health education, blindness from OAG should become increasingly rare. Much greater challenges face poor and emerging economies and countries where there is not equal access to good healthcare. The potential effectiveness of screening for OAG in preventing optic nerve damage and ultimately preventing blindness should be tested by high quality RCTs of screening.

\section{B A C K G ROU N D}

\section{Introduction}

Open angle glaucoma (OAG) is a primary, progressive optic neuropathy, the commonest of a spectrum of diseases grouped under the broad heading of glaucoma in Caucasian and African populations. The onset of OAG is without symptoms and progression occurs silently until the advanced stages of the disease, when it encroaches on central vision. The blindness caused by OAG is irreversible. Owing to this and to the insidious nature of the onset and progression of the disease, it has often been assumed that OAG is a condition that fulfils the criteria for population screening. However, a number of in-depth non-systematic reviews failed to come to that conclusion (Eddy 1983; Spry 2002; Wormald 1995). Problems identified were the lack of a single suitable screening test, uncertainty about the effectiveness of treatment and poor knowledge of the natural history of OAG.

More recently, new evidence has emerged on the effectiveness of treatment (Maier 2005; Rolim de Moura 2007; Vass 2007) and a number of new screening devices have been developed. There have also been reports of combinations of tests performing more efficiently than a single test in detecting the disease (Crick 1994; Crick 1995; Tuck 1993). The focus of this review was on the effectiveness of screening for OAG and excludes narrow or closed angle, congenital and secondary glaucomas. 


\section{Epidemiology}

Glaucoma is a common cause of blindness worldwide. Prevalence varies in different ethnic groups, with African races estimated as having a four to five times greater prevalence of OAG than ethnic Europeans or Asians (Buhrmann 2000; Hyman 2001; Leske 1994). This condition is thought to account for between $0.8 \%$ to $3 \%$ of blindness in Caucasians (Cedrone 1997; Dielemans 1994; Tielsch 1991; Wensor 1998) and as much as $28 \%$ in races of African origin (Hyman 2001).

Risk factors for developing OAG include increasing age, raised intraocular pressure (IOP), a family history of the disease, myopia and African ethnic origin (Leske 1994; Mitchell 1999; Sommer 1991; Wolfs 1998).

The average age at diagnosis has been estimated as 62 years in non-white populations and 70 years in white populations (Leske 1983).

\section{Presentation and diagnosis}

The onset of OAG is painless and with insidious loss of visual function, most notably of the field of vision. Changes in optic nerve head appearance are generally thought to precede abnormalities of the visual field, although this is not always the case. Raised IOP is commonly associated with OAG but is now known not to be as specific an indicator for the disease as once thought. Open angle glaucoma is characterised by an open anterior chamber drainage angle and the absence of any other putative causative factors such as pigment dispersion syndrome, a history of exposure to steroid medication or pseudoexfoliation.

\section{Optic nerve changes}

The initial changes in the optic nerve head are vertical extension of the central cup and notching of the neuroretinal rim, which may be preceded by focal splinter haemorrhages in the neuroretinal rim (termed 'disc haemorrhages'). Further thinning of the neuroretinal rim occurs with progression - typically inferotemporally and superotemporally, then extending to the nasal side. Pathological appearances of the optic nerve head in glaucoma are said to be typical, though not specific, since these changes can also be observed in persons with normal optic nerve function or non-progressive pathology.

\section{Visual field changes}

The earliest abnormalities in visual field sensitivity occur in the paracentral region or in the 'nasal step' area about 25 to 30 degrees from fixation with asymmetry in sensitivity across the horizontal meridian on the nasal side. New areas of relative loss of sensitivity occur in an arcuate fashion above or below the blind spot (Bjerrum's area), which extend with time to the periphery as they be- come more profound in depth. Eventually, a central island with a temporal crescent of sensitivity remains.

Up until this point central acuity may remain unaffected and then it may quite suddenly fail. Sadly, especially in poorer countries, this may be when the sufferer first becomes aware of the condition.

\section{Intraocular pressure changes}

Raised intraocular pressure is a major risk factor for the development of OAG. It was previously thought that raised IOP was part of the disease definition but epidemiological studies that revealed the presence of glaucoma without raised IOP, and raised IOP without glaucoma, led to re-evaluation of the relationship between the two. Nevertheless, there remains firm evidence of a causal relationship (Bahrami 2006) and the majority of interventions for glaucoma are aimed at reduction of IOP. Pressure above $21 \mathrm{~mm} \mathrm{Hg}$ in adults is generally accepted as being significantly raised; this is based on statistical observations of mean IOP, with $22 \mathrm{~mm} \mathrm{Hg}$ being greater than the mean IOP by twice the standard error of the mean.

\section{Natural History}

Open angle glaucoma nearly always affects both eyes but there is often a degree of asymmetry with one eye having more advanced disease than the other at presentation. In these situations, a relative afferent pupillary defect can be detected. The natural history of OAG is not well described. Much attention is given to early detection of the disease because late presentation is a risk factor for blindness. However, we do not know what proportion of early presenters are at risk of progressing to severe visual loss. It is probable that rates of progression vary and that determinants of this variance may include higher IOP but also vulnerability of the optic nerve. Because of this, there is a growing interest in measuring rates of progression in glaucoma so that appropriate treatment can be implemented. For screening, many now realise that tests for reliable detection of definite disease are more important than early detection.

\section{Diagnosis}

Tests for glaucoma involve: assessment of structural changes at the optic nerve head and the progression of these changes; functional visual loss assessed by visual field testing; and the level of IOP. A diagnosis of OAG is based principally on the presence of glaucomatous optic neuropathy affecting the appearance of the optic disc or retinal nerve fibre layer in the presence of a normal drainage angle. Definitions of abnormality are derived from describing normal population distributions and require the combination of corroborating diagnostic elements (Foster 2002). The availability of normative data for different technologies and different populations is limited. 
Structural loss: the optic nerve is assessed clinically by ophthalmoscopy or photography, or both. New techniques for assessment of the structural changes of the optic nerve have emerged.

1. The confocal scanning laser ophthalmoscope, commercially available as the Heidelberg Retinal Tomogram (HRT), produces a topographical image of the optic disc and peripapillary retina. The second-generation instrument, HRTII, is portable and may have better acceptability as a screening test in a primary care setting than the original HRT.

2. Scanning laser polarimetry (SLP) quantifies the thickness of the nerve fibre layer. Scanning laser polarimetry is available commercially (GDx) and has recently been modified to compensate for the variable properties of the cornea (GDx VCC) with improved performance characteristics.

3. Optical coherence tomography (OCT) and the retinal thickness analyser (RTA) have been introduced recently as possible tools to identify early glaucoma.

Functional loss: the accepted standard for measuring glaucomatous visual field loss is standard automated perimetry (SAP). The Humphrey visual field analyser is the most commonly used technology of SAP. Other tests of visual function purporting to detect disease at an earlier stage than SAP include frequency doubling perimetric techniques (FDT), short wave automated perimetry (SWAP) and motion perimetry. Other functional tests are available to detect established but early visual field loss, for example 'oculokinetic' perimetry $(\mathrm{OKP})$, suprathreshold perimetry and motion detection perimetry.

Intraocular pressure (IOP): the most widely used and generally accepted method for measuring IOP is contact applanation tonometry; where a prism is used to apply a force to the cornea to indent and flatten its surface (Goldmann 1955). Contact tonometers include the Goldmann, the Perkins and the Tonopen. Non-contact tonometers applanate the cornea with a puff of air (Shields 1980). Inaccuracies in IOP measurement can be induced by measurement technique and by variability of the central corneal thickness.

A systematic review of the diagnostic accuracy of screening tests for OAG is currently underway and information on the progress of this project can be found on the Health Technology Assessment website (http://www.hta.nhsweb.nhs.uk/ProjectData/1_project_ record_published.asp?PjtId=1027\&Search Text=). This review which includes economic modelling should help define the most appropriate screening test strategies and cut off criteria for onward referral.

\section{Screening for glaucoma}

To the best of our knowledge there are no formal glaucoma screening programmes with defined 'at risk' target populations and interval screening in existence in any country. However, a number of ad hoc strategies exist. In the USA, the American Academy of Ophthalmologists recommend screening in healthy adults with no risk factors at least once between the ages of 20 and 29 years, twice between 30 and 39 years, every 2 to 4 years between 40 to 64 years and every 1 to 2 years when aged 65 and older. However, funding support varies from state to state and is often non-existent. The International Glaucoma Association (IGA) have likewise made recommendations on screening and in Britain, free sight tests are offered to persons over 40 years of age if there is a history of an affected first-degree relative. However, this does not constitute a formal attempt to reach and test everyone at risk in a defined population and is perhaps better termed opportunistic surveillance rather than screening (Wormald 1995). Guidelines are provided by the British College of Optometrists indicating which tests should be done and when but these are not enforced. Uptake of sight testing by the British population is variable and the less well educated and more deprived communities are less likely to seek testing (Fraser 2001).

Ideally, guidelines for screening for OAG should be based on evidence of effectiveness in studies designed so that the participants in the screened and unscreened arms are essentially the same age with the same baseline risk for the disease. To achieve this, randomisation within birth year cohorts is essential. For example, in a study of 200 general practices, everyone aged 40 to 45 years in a randomly sampled 100 practices would be invited for glaucoma screening. Five years later, everyone who was invited for initial screening and everyone 45 to 50 years of age in the previously unscreened 100 practices would be invited for screening. The study might be powered on the assumption that the prevalence of glaucoma causing visual impairment sufficient to disqualify fitness to drive would be lower in the screened population since more cases would have been detected at an earlier stage of the disease and successfully treated.

\section{Treatment options}

In a systematic review of treatment effectiveness, IOP lowering treatment was found to be effective for reducing glaucoma progression (Maier 2005). Other ongoing or completed Cochrane reviews (Burr 2005; Rolim de Moura 2007; Sycha 2003; Vass 2007) provide further details on the effectiveness of various treatment options. The focus of this review was on evaluating the effectiveness of screening.

\section{Rationale for a systematic review}

The challenge of screening for OAG is to detect the disease at a stage where it is sufficiently present to be accurately identified in those individuals who are at risk of going blind in their lifetime if left untreated. Detecting very early disease may not necessarily be the most effective and efficient way to screen if resources are to be focused on those at risk of blindness. Attempting to detect the condition in its very early stages is likely to generate more false positive errors and identify numerous people whose sight is not 
threatened. Ultimately, the effectiveness of screening as a means of preventing the adverse effects of a disease in a population can be demonstrated only by randomised trials of screening where individuals or clusters of individuals are randomised to be screened, or not, thereby testing the hypothesis that screened individuals will have a lower risk of suffering the effects of the disease than the unscreened individuals. The randomised controlled trial (RCT) is the only study design that can deal with both length bias and lead time bias (Warwick 2005), if the appropriate outcomes have been selected. The rationale of this review was to systematically search and review RCTs of screening for OAG.

\section{O B J E C T I VES}

To determine the impact of screening for open angle glaucoma (OAG) compared with opportunistic case finding and current referral practices on the prevalence and severity of optic nerve damage due to OAG in screened and unscreened populations. This assumes that successful detection and subsequent treatment of OAG leads to a lower prevalence of advanced optic nerve damage in screened versus unscreened populations.

\section{METHODS}

\section{Criteria for considering studies for this review}

\section{Types of studies}

Randomised controlled trials (RCTs) of screening versus no screening for open angle glaucoma (OAG) were eligible for inclusion. We anticipated that eligible studies would take the form of cluster RCTs. Relevant RCTs would be those that contrasted screening with no screening. The reference strategy of no screening could include case finding, that is opportunistic screening. We did not include trials that compared different screening strategies.

We considered any method of randomisation, including those in which individuals, locations or practices were randomised. Differences in study quality were taken into account in the analysis. Ideally, trials would have analysed data on an intention-to-treat basis. We planned to include other types of analysis and use an available case-based analysis provided that all randomised participants were accounted for.

\section{Types of participants}

We considered studies from any population and reported major differences in the populations studied, such as age at screening and race when analysing the results. We expected persons already known to have glaucoma, already under the care of an eye specialist or known to be visually impaired for other reasons not to have been included in routine screening. Screening was likely to detect other degenerative eye conditions and other forms of glaucoma (including secondary open angle disease such as pseudoexfoliative and pigment dispersion glaucoma) though these were not included as the primary outcome of the review.

\section{Types of interventions}

Studies of any screening modality for OAG were eligible. We noted different screening techniques and considered any knowledge of test sensitivity and specificity in the discussion of the results

\section{Types of outcome measures}

\section{Primary outcomes}

We considered any or all of the following three primary outcomes for this review; measured at a minimum of one year postscreening. 1. Prevalence of any degree of characteristic visual field loss in screened and non-screened populations as diagnosed by any automated or manual visual field assessment (excluding confrontation). The proportion of persons with a predetermined severity of field loss (attributable to glaucoma) were compared in the screened and unscreened populations. The severity should correlate with existing trials for the prevention of OAG, for example, the European Glaucoma Prevention Study (EGPS) or the Ocular Hypertension Treatment Study (OHTS).

2. Prevalence of optic nerve damage in screened and non-screened populations as diagnosed by any method of imaging. Differences in the prevalence of a prespecified degree of structural optic nerve damage was examined in screened and unscreened populations. 3. Prevalence of visual impairment in screened and non-screened populations as defined by number of participants certified or registered according to national or regional (where the study was conducted) standards:

i. blind;

ii. partially sighted; iii. vision below standard for driving.

\section{Secondary outcomes}

Screening may lead to more treatment and subsequently to a lower mean intraocular pressure (IOP) in screened than unscreened populations. Intraocular pressure is a surrogate outcome but, nevertheless, indirect evidence of the effectiveness of screening could be derived from a reduction in the severity of this most well-established and modifiable risk factor. Any differences in mean IOP in screened and unscreened populations would be reported at a minimum of one year postscreening. 


\section{Adverse effects (severe, minor)}

Severe: false negatives results in persons with glaucoma who pass screening and go on to lose vision.

Minor: false positives results in persons without glaucoma who fail screening and are referred for further investigation but who do not undergo any treatment. Referral causes an excess burden on health services and unnecessary inconvenience and anxiety for individuals.

\section{Quality of life measures}

Various vision-specific quality of life measures are in use, for example the Visual Function Questionnaire (VFQ) and the National Eye Institute Visual Function Questionnaire (NEI VFQ25). Other glaucoma specific measures such as the GLQ15 (Nelson 2003) have been shown to correlate better with objective measures of disease progression.

The impact of glaucoma on health status (utility valuation) can be assessed using preference-based measures. These include time trade off, standard gamble (using a gamble of death or blindness, for example), the EQ5D (EuroQol 1990) and the Health Utilities Index Mark111 (HUI3) (Horsmann 2003). Any measures of quality of life or health status attributable to the screening or OAG would be reported.

\section{Economic data}

We planned to report any economic data available on the costs and cost-effectiveness of programme implementation, cost per case identified or other costs relating to the screening programme. Economic data are often the products of the aggregation of other data; for example, total cost would be an aggregate of the costs of the intervention plus the cost-consequences of that intervention, such as the treatment of complications. The methods and reporting of such aggregation can also be quality assessed. Where economic data (costs, economic measures of effectiveness such as quality adjusted life years, and cost-effectiveness) are reported additional quality assessment is required. We intended to use the Drummond checklist for the critical appraisal of economic evaluations (Drummond 1997).

\section{Other outcomes}

We planned to report any technical differences between the screening and control interventions, the quality of the intervention including any quality control measures, rates of participation, contamination and follow up in the screening and control arms.

\section{Follow-up}

A minimum follow up of one year postscreening was required for study inclusion. Where follow up varied between included studies this would be recorded and reported in the discussion.

\section{Search methods for identification of studies}

\section{Electronic searches}

We searched the Cochrane Central Register of Controlled Trials (CENTRAL) (which contains the Cochrane Eyes and Vision Group Trials Register) (The Cochrane Library, Issue 4, 2008), MEDLINE (January 1950 to January 2009), EMBASE (January 1980 to January 2009), the UK Clinical Trials Gateway (UKCTG) and ZETOC (January 1993 to January 2009). There were no language or date restrictions in the search for trials. The electronic databases were last searched on 12 January 2009.

See: Appendices for details of search strategies for CENTRAL (Appendix 1), MEDLINE (Appendix 2), EMBASE (Appendix 3), UKCTG (Appendix 4) and ZETOC (Appendix 5).

\section{Searching other resources}

We carried out no manual handsearching of journals or conference proceedings for this review although, if possible, these will be included in any updates. Regular contact with experts in the field should allow discovery of any unpublished or ongoing trials.

\section{Data collection and analysis}

\section{Assessment of search results}

Two review authors (RW, SH) independently assessed all titles and abstracts from the electronic searches. We did not identify any trials meeting the inclusion criteria for this review but in future updates we will obtain full reports for any studies that appear to be eligible and contact study authors if there is insufficient information in the full report, in order to enable inclusion wherever possible. Any disagreement between authors RW and $\mathrm{SH}$ regarding the inclusion of studies will be resolved by discussion with the third review author (JB). Details of excluded studies will be documented in the appropriate section of the review.

\section{Methods to be used in updates to the review}

For updates of this review, we will include any trial reports that become available in the future using the following methods.

\section{Assessment of methodological quality}

Each eligible study will be independently assessed for methodological quality by two authors ( $\mathrm{SH}, \mathrm{RW})$. Each of the following parameters will be graded as either Yes (indicating adequate measures were taken and there is therefore a low risk of bias), No (indicating adequate measures were not taken and there is therefore a high risk of bias), or Unclear, as outlined in Chapter 8 of the Cochrane Handbook for Systematic Reviews of Interventions (Higgins 2008a). Additional information from study authors will be sought if any 
criteria are graded unclear. Any disagreements will be resolved by discussion with the third author (JB).

The following potential areas of bias will be examined for quality.

1. Sequence generation

We will note methods used to generate the random sequence and what method of randomisation was used. We will include studies where communities were randomly selected for screening or no screening and then compared with each other after a period of follow up.

2. Allocation concealment

We will assess how adequately allocation was concealed until after the intervention was assigned.

3. Masking (blinding)

Assessor masking will be graded according to whether it was present or absent. We anticipate that assessors will be unaware of the previous screening status of individuals when assessing outcome.

Participants in the screened arm of any study included in this review will be aware of their allocated intervention. Those not screened may not be aware that they are in the control arm until follow up.

4. Incomplete outcome data

Some loss to follow up will be inevitable, and in the design mentioned above, this will only be quantifiable in the previously screened population. Where this is greater than $20 \%$, the validity of the study will be questioned if there is no information on the characteristics of those lost to follow up or on whether their loss may have introduced bias in the outcome.

5. Selective reporting

We expect data to be analysed on an intention-to-treat basis as defined in the Cochrane Handbook for Systematic Reviews of Interventions (Higgins 2008b) or at least on an available case-based analysis where participants are analysed as randomised. Where data are missing or unclear the authors will be contacted for further information.

6. Other biases

\section{Economic assessment}

The Drummond checklist for the critical appraisal of economic evaluations (Drummond 1997) asks a series of questions relating to the quality of the economic component of the study for which the answers are classed as: Yes, No or Cannot tell.

1. Was a well-defined question posed in an answerable form?

2. Was a comprehensive description of the competing alternatives given (that is, can you tell who did what, to whom, where, and how often)?

3. Was there evidence that the programme's effectiveness had been established?

4. Were all important and relevant costs and consequences for each alternative identified?
5. Were costs and consequences measured accurately in appropriate physical units?

6. Were costs valued credibly?

7. Were consequences valued credibly?

8. Were costs adjusted for differential timing?

9. Were consequences adjusted for differential timing?

10. Was an incremental analysis of costs and consequences of alternatives performed?

11. Did the presentation and discussion of study results include all issues of concern to users?

Studies that do not present a full economic evaluation (studies that report only costs or economic measures of effects) will only be assessed against those questions that are relevant.

\section{Data collection}

Two authors (SH, RW) will independently undertake the data extraction for eligible studies using the relevant forms developed by the Cochrane Eyes and Vision Group. The extracted data will be compared for differences and discrepancies will be resolved by discussion.

\section{Data entry}

Both authors involved in the data extraction will independently enter the extracted data into RevMan using the double-entry facility to check for errors. If data are missing or unclear we will attempt to contact the authors for more information.

\section{Data synthesis}

Comparisons will be made between screened and unscreened populations; if appropriate, results from included trials will be combined in a meta-analysis using a random-effects model unless there are very few trials in which case a fixed-effect model will be used. Odds ratios and risk differences will be used to assess the impact of screening of the risk of severe optic nerve damage from OAG. Mean difference will be used to compare intraocular pressure (IOP) levels in screened and unscreened populations. If significant heterogeneity exists no meta-analysis will be conducted and we will present a narrative summary.

As it is anticipated that cluster randomisation may be used in the included studies we will use the appropriate methods for dealing with this as outlined in Chapter 16 of the Cochrane Handbook for Systematic Reviews of Interventions (Higgins 2008b).

\section{Subgroup analysis}

Where possible we will compare the effectiveness of different screening strategies to no screening or current practice in the following subgroup analysis. 
- Screening by optic nerve imaging, visual field assessment or IOP measurement alone compared with any combination of these tests.

\section{Assessment of heterogeneity}

We will assess for heterogeneity initially by examining the characteristics of the included studies and looking at the overlap in confidence intervals of the forest plots. Testing for statistical heterogeneity will be observed with the chi-squared test provided in RevMan. Additionally, we will use the I-squared statistic to quantify inconsistency between studies.

\section{Sensitivity analysis}

We will conduct sensitivity analyses by repeating the analysis and excluding studies of lower methodological quality, that is graded $\mathrm{B}$ or $\mathrm{C}$ on any parameter, or if assessor masking was absent.

\section{RES U L T S}

\section{Description of studies}

The electronic searches identified 1360 reports of studies but none fulfilled the inclusion criteria for the review. An update search was done in January 2009. After deduplication the search identified a total of 846 references. The Trials Search Co-ordinator scanned the search results and removed any references which were not relevant to the scope of the review. Two authors independently reviewed the remaining references. We reviewed the full text for one study (Stoutenbeek 2008) and found it to be ineligible for inclusion. Overall we did not find any reports of studies that were eligible for inclusion.

\section{Risk of bias in included studies}

As no trials met the inclusion criteria, we assessed none for quality.

\section{Effects of interventions}

Since no randomised controlled trials were identified, we extracted no data and performed no analyses.

\section{I S C USSION}

The management of open angle glaucoma has changed over the last 20 years as evidence on the effectiveness of treatment has emerged.
Lack of this evidence acted as an impediment to the implementation of screening but despite improved clarity regarding treatment effectiveness uncertainties persist regarding the natural history of the disease.

Two major sources of bias that would otherwise distort the findings of observational studies can be dealt with only by randomised controlled trials of screening.

Lead time bias occurs when the condition is detected at an earlier stage through screening, although no influence on ultimate outcome is achieved as a result of that earlier detection. The survival is apparently greater because the condition is known about for longer but an otherwise similar unscreened individual goes blind at the same rate but spends less time aware of the problem. In such a circumstance, it is fair to conclude that screening has done harm.

Length bias occurs because interval screening is more likely to detect slowly progressive and indolent disease than aggressive rapidly progressing glaucoma. Apparently, screening has led to the identification of more people with early stage disease being identified who are at much lower risk of blindness. This apparent benefit might actually be harmful if the risk of the adverse effects of disease in these mild cases is very low and the number of persons with aggressive blinding glaucoma remains the same and the blindness rates are unchanged. This point was specifically addressed in the Rotterdam study where incident cases identified in a cohort study were compared to those routinely identified by visiting optometrists (Stoutenbeek 2008).

This is why we specifically searched for RCTs of screening in this review; the only study design that can adequately deal with these two sources of bias. However, the organisation and conduct of such studies is demanding and long term follow up is required on large numbers of people if there is to be any likelihood of detecting an effect. It is perhaps not surprising that no such trials have been identified and the justification for such a study will depend on the refinement of screening test strategies and economic modelling of potential benefit and cost.

\section{AUTHORS' CONCLUSIONS}

\section{Implications for practice}

On the basis of current evidence, population based screening for open angle glaucoma (OAG) cannot be recommended. Much can be done to improve awareness of the condition and encourage at risk individuals to seek testing using optimised detection strategies, although it may not yet be clear what these are. Good clinical method remains vital for the correct diagnosis of the disease so that a prognosis and a treatment plan appropriate to that individual's estimated lifetime risk of sight loss can be made. In wealthy countries with equitable access to high quality eye care and good health 
education, blindness from OAG should become increasingly rare. Much greater challenges face poor and emerging economies and countries where there are substantial health and wealth inequalities.

\section{Implications for research}

The effectiveness of screening for OAG can be established only by high quality randomised trials. A number of preliminary issues need to be dealt with before such trials can be undertaken. A better understanding of testing technologies is needed and a much improved quality of research (using STARDT) in different populations is required to delineate optimum screening strategies in terms of individual tests and technologies, combinations of tests and test frequency. Economic modelling using the best tests delin- eated above will help to decide whether opportunity cost and cost benefit are potentially justifiable before committing to the longer term studies measuring health impact and sight years saved. Better monitoring of health outcomes in large populations using registers of blindness by cause can provide surveillance for the observation of the impact of prevention strategies over time.

\section{ACKNOW LEDGEMENTS}

We thank Luke Vale of the Health Services Research Unit at the University of Aberdeen, Augusto Azuara-Blanco, Catey Bunce, Swaroop Vedula and Scott Fraser for their comments. We thank the Eyes and Vision editorial team for creating and running the searches as well as their assistance throughout the review process.

\section{REFEREN CES}

\section{Additional references}

\section{Bahrami 2006}

Bahrami H. Causal inference in primary open angle glaucoma: specific discussion on intraocular pressure. Ophthalmic Epidemiology 2006;13(4):283-9.

Buhrmann 2000 Buhrmann RR, Quigley HA, Barron Y, West SK, Oliva MS, Mmbaga BB. Prevalence of glaucoma in a rural East African population. Investigative Ophthalmology \& Visual Science 2000;41(1):40-8.

Burr 2005

Burr J, Azuara-Blanco A, Avenell A. Medical versus surgical interventions for open angle glaucoma. Cochrane Database of Systematic Reviews 2004, Issue 2. [DOI: 10.1002/ 14651858.CD004399.pub2]

Cedrone 1997

Cedrone C, Culasso F, Cesareo M, Zapelloni A, Cedrone P, Cerulli L. Prevalence of glaucoma in Ponza, Italy: a comparison with other studies. Ophthalmic Epidemiology 1997;4(2):59-72.

\section{Crick 1994}

Crick RP. Epidemiology and screening of open angle glaucoma. Current Opinion in Ophthalmology 1994;5(2): 3-9.

Crick 1995

Crick RP, Tuck MW. How can we improve the detection of glaucoma?. BMJ 1995;310(6979):546-7.

Dielemans 1994

Dielemans I, Vingerling JR, Wolfs RC, Hofman A, Grobbee $\mathrm{DE}$, de Jong PT. The prevalence of primary open-angle glaucoma in a population-based study in the Netherlands. The Rotterdam Study. Ophthalmology 1994;101(11): 1851-5.

\section{Drummond 1997}

Drummond MF, O'Brien B, Stoddart GL, Torrance GW. Methods for the economic evaluation of health care programmes. 2nd Edition. Oxford: Oxford University Press, 1997.

Eddy 1983

Eddy DM, Sanders LE, Eddy JF. The value of screening for glaucoma with tonometry. Survey of Ophthalmology 1983; 28(3):194-205.

\section{EGPS}

Miglior S, Zeyen T, Pfeiffer N, Cunha-Vaz J, Torri V, Adamsons I. European Glaucoma Prevention Study (EGPS) Group. Results of the European Glaucoma Prevention Study. Ophthalmology 2005;112(3):366-75.

\section{EuroQol 1990}

The EuroQol Group. EuroQol: a facility for measurement of health related quality of life. Health Policy 1990; Vol. 16:199-268.

\section{Foster 2002}

Foster PJ, Buhrmann R, Quigley HA, Johnson GJ. The definition and classification of glaucoma in prevalence surveys. British Journal of Ophthalmology 2002;86(2): $238-42$.

Fraser 2001

Fraser S, Bunce C, Wormald R, Brunner E. Deprivation and late presentation of glaucoma; case-control study. $B M J$ 2001;322(7287):639-43.

\section{Glanville 2006}

Glanville JM, Lefebvre C, Miles JN, Camosso-Stefinovic J. How to identify randomized controlled trials in MEDLINE: ten years on. Journal of the Medical Library Association 2006; 94(2):130-6.

\section{Goldmann 1955}

Goldmann H. [Un nouveau tome re d'applanation]. Bulletin de la Societe Belge d'Ophtalmologie 1955;67:474-8. 
Higgins 2008a

Higgins JPT, Altman DG (editors). Chapter 8: Assessing risk of bias in included studies. In: Higgins JPT, Green $S$ (editors). Cochrane Handbook for Systematic Reviews of Interventions Version 5.0.1 (updated September 2008). The Cochrane Collaboration, 2008. Available from www.cochrane-handbook.org.

Higgins 2008b

Higgins JPT, Deeks JJ, Altman DG (editors). Chapter 16: Special topics in statistics. In: Higgins JPT, Green S (editors). Cochrane Handbook for Systematic Reviews of Interventions Version 5.0.1 (updated September 2008). The Cochrane Collaboration, 2008. Available from www.cochrane-handbook.org.

Horsmann 2003

Horsmann J, Feelong W, Feeney D, Torrance G. The health utilities index (HUI). Concepts, measurement properties, and application. Health Related Quality of Life Outcomes 2003; Vol. 1:54.

Hyman 2001

Hyman L, Wu SY, Connell AM, Schachat A, Nemesure B, Hennis A, et al.Prevalence and causes of visual impairment in the Barbados Eye Study. Ophthalmology 2001;108(10): $1751-6$.

Leske 1983

Leske MC. The epidemiology of open-angle glaucoma: a review. American Journal of Epidemiology 1983;118(2): 166-91.

\section{Leske 1994}

Leske MC, Connell AM, Schachat AP, Hyman L. Barbados Eye Study. Prevalence of open angle glaucoma. Archives of Ophthalmology 1994;112(6):821-9.

\section{Maier 2005}

Maier PC, Funk J, Schwarzer G, Antes G, Falck-Ytter YT. Treatment of ocular hypertension and open angle glaucoma: meta analysis of randomised controlled trials. BMJ 2005; 331(7509): 134 .

\section{Mitchell 1999}

Mitchell P, Hourihan F, Sandbach J, Wang JJ. The relationship between glaucoma and myopia: the Blue Mountains Eye Study. Ophthalmology 1999;106(10): 2010-5.

Nelson 2003

Nelson P, Aspinall P, O'Brien C. Quality of life in glaucoma and its relationship with visual function. Journal of Glaucoma 2003;12(2):139-50.

\section{OHTS}

Kass MA, Heuer DK, Higginbotham EJ, Johnson CA, Keltner JL, Miller JP, et al.The Ocular Hypertension Treatment Study: a randomized trial determines that topical ocular hypotensive medication delays or prevents the onset of primary open-angle glaucoma. Archives of Ophthalmology 2002;120(6):701-13.

Rolim de Moura 2007

Rolim de Moura C, Paranhos A, Wormald R. Laser trabeculoplasty for open angle glaucoma. Cochrane Database of Systematic Reviews 2007, Issue 4. [DOI: 10.1002/

14651858.CD003919.pub2]

\section{Shields 1980}

Shields MB. The non-contact tonometer: its value and limitations. Survey of Ophthalmology 1980;24(4):211-9.

\section{Sommer 1991}

Sommer A, Tielsch JM, Katz J, Quigley HA, Gottsch JD, Javitt J, et al.Relationship between intraocular pressure and primary open angle glaucoma among white and black Americans. The Baltimore Eye Survey. Archives of Ophthalmology 1991;109(8):1090-5.

Spry 2002

Spry PG, Johnson CA. Identification of progressive glaucomatous visual field loss. Survey of Ophthalmology 2002;47(2):158-73.

\section{Stoutenbeek 2008}

Stoutenbeek R, De Voogd S, Wolfs RCW, Hofman A, Dejong PTVM, Jasonius NM. The additional yield of a periodic screening programme for open-angle glaucoma: a population-based comparison of incident glaucoma cases detected in regular ophthalmic care with cases detected during screening. British Journal of Ophthalmology 2008;92 (9):1222-6.

\section{Sycha 2003}

Sycha T, Vass C, Findl O, Bauer P, Groke I, Schmetterer L, et al.Interventions for normal tension glaucoma. Cochrane Database of Systematic Reviews 2003, Issue 1. [DOI: 10.1002/14651858.CD002222]

\section{Tielsch 1991}

Tielsch JM, Katz J, Singh K, Quigley HA, Gottsch JD, Javitt J, et al.A population-based evaluation of glaucoma screening: the Baltimore Eye Survey. American Journal of Epidemiology 1991;134(10):1102-10.

\section{Tuck 1993}

Tuck MW, Crick RP. Relative effectiveness of different modes of glaucoma screening in optometric practice. Ophthalmic and Physiological Optics 1993;13(3):227-32.

Vass 2007

C Vass, C Hirn, T Sycha, O Findl, S Sacu, P Bauer, et al.Medical interventions for primary open angle glaucoma and ocular hypertension. Cochrane Database of Systematic Reviews 2007, Issue 4. [DOI: 10.1002/ 14651858.CD003167.pub3]

\section{Warwick 2005}

Warwick J, Duffy SW. A review of cancer screening evaluation techniques, with some particular examples in breast cancer screening. Journal of the Royal Statistical Society: Series A (Statistics in Society) 2005;168(4):657-77.

\section{Wensor 1998}

Wensor MD, McCarty CA, Stanislavsky YL, Livingston PM, Taylor HR. The prevalence of glaucoma in the Melbourne Visual Impairment Project. Ophthalmology 1998;105(4):733-9. 


\section{Wolfs 1998}

Wolfs RC, Klaver CC, Ramrattan RS, van Duijn CM,

Hofman A, de Jong PT. Genetic risk of primary open-angle glaucoma. Population-based familial aggregation study. Archives of Ophthalmology 1998;116(12):1640-5.

\section{Wormald 1995}

Wormald RP, Rauf A. Glaucoma screening. Journal of Medical Screening 1995;2(2):109-14.

* Indicates the major publication for the study 


\section{DATA ANDANALYSES}

This review has no analyses.

\section{A P P E N D I C ES}

\section{Appendix I. CENTRAL search strategy}

\#1 MeSH descriptor Glaucoma, Open-Angle

\#2 open near/2 angle near/2 glaucoma*

\#3 MeSH descriptor Ocular Hypertension

\#4 ocular near/2 hypertensi*

\#5 MeSH descriptor Intraocular Pressure

\#6 intraocular near/2 pressure*

\#7 POAG or IOP or OHT

\#8 ((increas* or elevat* or high*) near/3 (ocular or intra-ocular) near/3 (pressure))

\#9 (\#1 OR \#2 OR \#3 OR \#4 OR \#5 OR \#6 OR \#7 OR \#8)

\#10 MeSH descriptor Vision Screening

\#11 MeSH descriptor Mass Screening

\#12 MeSH descriptor Vision Disorders

\#13 MeSH descriptor Vision Tests

$\# 14$ (test* or screen* or diagnos* or assess*) near/5 (vision or pressure* or hypertensi*)

\#15 (\#10 OR \#11 OR \#12 OR \#13 OR \#14)

\section{Appendix 2. MEDLINE search strategy}

1 randomized controlled trial.pt.

2 (randomized or randomised).ab,ti.

3 placebo.ab,ti.

4 dt.fs.

5 randomly.ab,ti.

6 trial.ab,ti.

7 groups.ab,ti.

8 or/1-7

9 exp animals/

10 exp humans/

119 not (9 and 10)

128 not 11

13 exp glaucoma/

14 exp glaucoma open angle/

15 (open adj2 angle adj2 glaucoma\$).tw.

16 exp ocular hypertension/

17 (ocular adj2 hypertensi\$).tw.

18 exp intraocular pressure/

19 (intraocular adj2 pressure\$).tw.

20 (OAG or IOP or OHT).tw.

21 (( (increas\$ or elevat\$ or high\$) adj3 (ocular or intra-ocular)) and pressure).tw.

22 exp cornea/

Screening for prevention of optic nerve damage due to chronic open angle glaucoma (Review)

Copyright $\odot 2009$ The Cochrane Collaboration. Published by John Wiley \& Sons, Ltd. 
23 cornea $\$$ thick\$.tw.

24 or/ $13-23$

25 exp vision screening/

26 exp mass screening/

27 exp vision disorders/

28 exp vision tests/

29 screen $\$$.tw.

30 or/ $25-29$

3124 and 30

3212 and 31

3124 and 30

3212 and 31

The search filter for trials at the beginning of the MEDLINE strategy is from the published paper by Glanville et al (Glanville 2006).

\section{Appendix 3. EMBASE search strategy}

1 exp randomized controlled trial/

2 exp randomization/

3 exp double blind procedure/

4 exp single blind procedure/

5 random $\$$.tw.

6 or/ $1-5$

7 (animal or animal experiment).sh.

8 human.sh.

97 and 8

107 not 9

116 not 10

12 exp clinical trial/

13 (clin $\$$ adj3 trial\$).tw.

14 ((singl\$ or doubl\$ or trebl\$ or tripl\$) adj3 (blind $\$$ or mask $\$)$ ).tw.

15 exp placebo/

16 placebo\$.tw.

17 random\$.tw.

18 exp experimental design/

19 exp crossover procedure/

20 exp control group/

21 exp latin square design/

22 or/ $12-21$

2322 not 10

2423 not 11

25 exp comparative study/

26 exp evaluation/

27 exp prospective study/

28 (control\$ or prospectiv\$ or volunteer\$).tw.

29 or $/ 25-28$

3029 not 10

3130 not (11 or 23$)$

3211 or 24 or 31

33 exp glaucoma/

34 exp open angle glaucoma/

35 (open adj2 angle adj2 glaucoma \$).tw.

36 exp intraocular hypertension/

Screening for prevention of optic nerve damage due to chronic open angle glaucoma (Review)

Copyright $\odot 2009$ The Cochrane Collaboration. Published by John Wiley \& Sons, Ltd. 
37 (ocular adj2 hypertens $\$$ ).tw.

38 exp intraocular pressure/

39 (intraocular adj2 pressure\$).tw.

40 (POAG or IOP or OHT).tw.

41 (( (increas\$ or elevat\$ or high\$) adj3 (ocular or intra-ocular)) and pressure).tw.

42 exp cornea/

43 cornea $\$$ thick $\$$.tw.

44 or/34- 41

45 exp vision test/

46 exp mass screening/

47 exp school health services/

48 exp child health care/

49 exp vision disorder/

50 screen\$.tw.

51 or $/ 45-50$

5244 and 51

5332 and 52

\section{Appendix 4. UK Clinical Trials Gateway (UKCTG) search strategy}

glaucoma* and screen*

\section{Appendix 5. ZETOC search strategy}

glaucoma* AND screen* AND optic nerve

\section{WHAT'S NEW}

Last assessed as up-to-date: 11 January 2009.

\begin{tabular}{lll}
\hline Date & Event & Description \\
\hline 28 November 2008 & New search has been performed & Issue 2, 2009: updated searches yielded no new trials. \\
\hline
\end{tabular}

\section{H I S T O R Y}

Protocol first published: Issue 3, 2006

Review first published: Issue 4, 2006 


\begin{tabular}{l|l|l}
\hline Date & Event & Description \\
\hline 16 October 2008 & Amended & Converted to new review format. \\
\hline
\end{tabular}

\section{CONTRIBUTIONS OFAUTHORS}

Conceiving the review: RW, JB

Designing the review: RW, $\mathrm{SH}, \mathrm{JB}$

Coordinating the review: RW, $\mathrm{SH}$

Designing search strategies: CEVG Trials Search Co-ordinator

Undertaking searches: CEVG Trials Search Co-ordinator

Screening search results: RW, SH

Organising retrieval of papers: RW, SH, CEVG Trials Search Co-ordinator

Screening retrieved papers against inclusion criteria: RW, SH

Appraising quality of papers: RW, SH

Extracting data from papers: RW, $\mathrm{SH}$

Writing to authors of papers for additional information: RW, SH

Providing additional data about papers: RW, JB

Obtaining and screening data on unpublished studies: RW, SH

Entering data into RevMan: RW, SH

Analysis of data: RW, JB, SH

Providing a methodological perspective: RW, JB

Providing a clinical perspective: RW, JB

Providing a policy perspective: RW, JB

Writing the review: RW, SH

Securing funding for the review: JB

Performing previous work that was the foundation of the current study: JB 


\section{DECLARATIONSOF INTEREST}

None known.

\section{SOURCES OF SUPPORT}

\section{Internal sources}

- Cochrane Eyes and Vision Group, UK.

\section{External sources}

- NHS R \& D Health Technology Assessment programme, UK.

\section{INDEX TERMS}

\section{Medical Subject Headings (MeSH)}

*Mass Screening; Glaucoma, Open-Angle [*diagnosis]; Optic Nerve Diseases [etiology; * prevention \& control]

\section{MeSH check words}

Humans 